\title{
ANALISIS KADAR BIOETANOL HASIL FERMENTASI DARI NIRA NIPAH (Nypa fruticans wurmb) ASAL PAPUA
}

\author{
Sefnat Sopater Runtuboi ${ }^{1 *}$, Maria Ludya Pulung ${ }^{1}$, Evelina Somar \\ Email : ludya_chemistry@yahoo.com, evelynsomar12@gmail.com, \\ sefnatruntuboi25@gmail.com,
}

\begin{abstract}
ABSTRAK
Penelitian ini bertujuan untuk menganalisis kadar etanol dalam nira nipah hasil fermentasi. Penelitian ini meliputi penyiapan bahan baku, fermentasi, destilasi dan hasil destilasi dianalisis dengan metode kromatografi gas. Fermentasi dilakukan selama 2, 5, 7 hari, bioethanol yang dihasilkan dipilih kadar tertinggi untuk selanjutnya didestilasi. Kadar tertinggi proses fermentasi yaitu pada hari ke-5 dengan kadar 18\%. Didapat hasil destilasi akhir yaitu $117 \mathrm{~mL}$ dengan kadar 94\% dari volume awal fermentasi 4,2 L berdasarkan pengukuran menggunakan alcoholmeter sedangkan analisis dengan kromatografi gas menghasilkan kadar 93,9\%. Densitas bioetanol yaitu $0,8232 \mathrm{gr} / \mathrm{mL}$. Hasil pengukuran waktu retensi menunjukan sampel memiliki waktu retensi yang hampir sama dengan etanol standar yakni sampel 3,761 etanol standar 3,764. Dari data waktu retensi dapat disimpulkan bahwa sampel adalah etanol. Kadar etanol dalam sampel berdasarkan analisis dengan kromatografi gas yaitu 93,9\%.
\end{abstract}

Kata Kunci : Nypa fruticans wurmb, Bioetanol, Fermentasi, Destilasi, Kromatografi Gas

\begin{abstract}
This study aims to analyze the ethanol content in fermented palm juice. This research includes the preparation of raw materials, fermentation, distillation and distillation products analyzed by gas chromatography method. Fermentation is carried out for 2, 5, 7 days, the highest level of bioethanol produced is then selected for distillation. Levels the highest fermentation process is on the 5th day with a level of 18\%. Got results the final distillation is $117 \mathrm{~mL}$ with a level of $94 \%$ of the initial volume of $4.2 \mathrm{~L}$ fermentation based on measurements using an alcoholmeter while the analysis by gas chromatography yielded 93.9\% levels. The density of bioethanol is $0.8232 \mathrm{gr}$ $/ \mathrm{mL}$. The results of the retention time measurement show the sample has a retention time which is almost the same as standard ethanol, namely 3,761 standard ethanol samples 3,764. From retention time data can be concluded that the sample is ethanol. Ethanol content in sample based on analysis by gas chromatography is $93.9 \%$
\end{abstract}

Key Words: Nypa fruticans wurmb, Bioethanol Fermentation, Distillation, Gas Cromatography 


\section{PENDAHULUAN}

Indonesia merupakan negara kepulauan yang memiliki berbagai macam flora dan fauna yang tersebar di tiga puluh empat provinsi yang ada di Indonesia. Flora atau dunia tumbuhan di berbagai tempat di dunia berbeda-beda. Hal ini dipengaruhi oleh beberapa faktor yaitu iklim, jenis tanah, relief atau tinggi rendah permukaan bumi, dan biotik atau pengaruh mahkluk hidup.

Papua memiliki berbagai macam jenis Flora yang di pengaruhi oleh curah hujan yang tinggi. Salah satu tumbuhan yang tersebar di alam Papua yaitu Nypa fruticans wurmb. Nypa fruticans wurmb adalah sejenis palem yang tumbuh di lingkungan hutan bakau atau daerah pasang surut dekat tepi pantai. Tanaman ini dapat melindungi daratan atau pantai dari abrasi air laut. Nypa fruticans wurmb dapat juga disadap niranya, yaitu cairan manis yang diperoleh dari tandan buah yang belum tua. Selama ini pemanfatan Nypa fruticans wurmb belum optimal, sebagian masyarakat dipesisir pantai memanfatkan Nypa fruticans wurmb dalam bentuk gula. Namun gula yang diperoleh memiliki rasa sedikit asin dan kurang disukai konsumen, sehingga pengolahan Nypa fruticans wurmb menjadi gula tidak maksimal (Tresnawati, 2009). Selain itu pemanfaatan nira nipah juga hanya sebagai minuman lokal. Salah satu alternatif pemanfaatan tanaman Nypa fruticans wurmb adalah sebagai bahan baku pembuatan bioethanol. Menurut (Dahlan at al., 2009) Nypa fruticans wurmb mengandung sukrosa sebesar 13-17 \%, ini merupakan suatu bahan yang potensial untuk diolah menjadi bioethanol.

Bioethanol merupakan suatu bentuk energy alternatif, karena dapat mengurangi ketergantungan terhadap bahan bakar minyak (Delly at al., 2016). Seperti yang tertuang dalam Peraturan Presiden Republik Indonesia Nomor 5 Tahun 2006 Tentang Kebijakan Energi Nasional, adalah melalui pengembangan energy terbarukan berbasis nabati atau atau sering disebut Bahan Bakar Nabati (BBN). Bioethanol adalah etanol yang diperoleh dari fermentasi dan destilasi bahan-bahan yang mengandung amilum, sukrosa, glukosa, dan fruktosa (Niastiwi, 2013). Proses destilasi hanya mampu menghasilkan etanol dengan kadar 96\% yang dinamakan campuran azeotopik (Khaidi at al., 2009). Secara teoritis kita tidak dapat menghasilkan bioethanol dengan kadar murni lebih dari 97,2\% melalui proses destilasi (Oniki, 2006).

\section{METODOLOGI PENELITIAN}

\section{Alat dan Bahan}

Alat-alat yang digunakan dalam penelitian ii adalah gelas wadah, rangkaian alat destilasi, rangkaian alat evaporator, labu leher tiga, termometer, alcoholmeter, mikropipet, timbangan analitik, gelas ukur, serangkaian alat kromatografi gas.

\section{Prosedur Kerja}

\section{Penyiapan Bahan Baku}

Nira nipah yang digunakan dalam penelitian ini diambil dari daerah Kabupaten Manokwari. Nira yang diperoleh disaring dengan tujuan pengotor yang ada pada nira hilang.

\section{Fermentasi}

Nira 4,2 L yang telah disaring dimasukkan ke dalam tiga botol kaca berukuran 5 L. Masukkan ragi sebanyak 300 gram kedalam masing-masing botol yang telah diisi nira diaduk beberapa menit agar tercampur rata. Setelah diaduk botol ditutup rapat dan dibiarkan selama 2, 5 dan 7 hari pada suhu ruangan. Setelah 2, 5 dan 7 hari masing-masing botol dibuka kemudian dimurnikan dengan cara destilasi.

\section{Distilasi}

Nira nipah hasil fermentasi terbaik dipilih untuk selanjutnya dimurnikan. Destilasi dilakukan pada suhu $78-86{ }^{\circ} \mathrm{C}$ sebanyak empat 
kali. ukur kadar alcohol setiap destilasi menggunakan alcoholmeter.

\section{Pengukuran Kadar Alkohol}

Alat yang digunakan untuk mengukur kadar alcohol adalah alcoholmeter. Pengukuran kadar alcohol dilakukan setiap destilasi. Langkah-langkah pengukuran menggunakan alkohometer (Feryanto, 2009) adalah dengan memasukan destilat sebanyak $100 \mathrm{ml}$ kedalam gelas ukur, kemudian alcoholmeter dicelupkan kedalam destilat.

\section{Rendemen Bioetanol}

Rendemen bioetanol dihitung dari hasil pengukuran volume bioetanol yang diperoleh dari destilasi nira nipah dibagi dengan volume bahan dasar atau produk awal (Suastini, 1994).

$$
\text { Rendemen } \%=\frac{\text { Volume produk akhir }}{\text { volume produk awal }} \times 100
$$

(Wijaya at al., 2012)

\section{Identifikasi Etanol}

Buat larutan campuran dari etanol standar dan propanol. Pipet sebanyak $1 \mathrm{~mL}$ etanol standar ke dalam labu ukur $50 \mathrm{~mL}$, tambahkan propanol standar $20 \% \quad 0,5 \quad \mathrm{~mL}$ kemudian tambahkan aquades sampai tanda batas. Pipet $0,1 \mu \mathrm{L}$ dan diinjeksikan ke alat kromatografi gas. Pada kondisi yang sama diinjeksikan campuran sampel dan propanol. Bila waktu retensi dari sampel sama dengan standar etanol, maka dapat disimpulkan bahwa sampel tersebut adalah etanol.

\section{Pembuatan Kurva Standar}

Disiapkan larutan standar etanol dengan konsentrasi $30 \%, 40 \%, 50 \%, 60 \%$, dan $70 \%$ sebagai berikut :
Tabel 3 Pembuatan Larutan Standar Etanol

\begin{tabular}{ccc}
\hline No & Etanol p.a $(\mathrm{mL})$ & $\begin{array}{c}\text { Konsentrasi akhir } \\
\text { etanol }(\% \mathrm{v} / \mathrm{v})\end{array}$ \\
\hline 1 & 30 & 30 \\
2 & 40 & 40 \\
3 & 50 & 50 \\
4 & 60 & 60 \\
5 & 70 & 70 \\
\hline
\end{tabular}

Etanol standar dengan jumlah pada Tabel 3 dimasukan ke dalam labu ukur $100 \mathrm{~mL}$ kemudian tambahkan aquades sampai tanda tabas. Pipet $1 \mathrm{~mL}$ larutan standar dari masingmasing konsentrasi ke dalam labu ukur $50 \mathrm{~mL}$. Tambahkan larutan propanol standar 20\% masing-masing $0,5 \mathrm{~mL}$ kedalam labu ukur 50 $\mathrm{mL}$ yang telah dahulu diisi standar etanol, kemudian tambahkan aquades sampai tanda batas. larutan campuran ini masing-masing diambil $0,1 \mu \mathrm{L}$ lalu diinjeksikan ke alat kromatografi gas.

Kurva standar dibuat dengan memplotkan kadar etanol $(\% \mathrm{v} / \mathrm{v})$ sebagai sumbu $\mathrm{X} v s$ perbandingan luas area etanol/propanol sebagai sumbu Y.

Pengukuran Kadar Etanol dengan GC

Pipet alcohol hasil destilasi $1 \mathrm{~mL}$ ke dalam labu ukur $100 \mathrm{~mL}$, kemudian pipet $1 \mathrm{~mL}$ ke dalam labu $50 \mathrm{~mL}$ tambahkan $0,5 \mathrm{~mL}$ propanol dan tambahkan air sampai tanda batas. campuran diambil $0,1 \mu \mathrm{L}$ dan diinjeksikan ke dalam kromatografi gas. Untuk perhitungan kadarnya dihitung luas area sampel banding luas area propanol. Nilai perbandingan tersebut kemudian digunakan untuk menentukan kadar etanol dengan menggunakan persamaan garis dari kurva standar.

\section{Densitas}

Densitas ditentukan mengikuti cara menurut Tjokrowisastro (1986). Mula-mula botol piknometer $100 \mathrm{ml}$ yang kosong ditimbang. Setelah itu kedalam piknometer tersebut dimasukkan sampel hasil destilasi 
sampai penuh dan ditimbang kembali. Densitas dihitung dengan persamaan:

$\rho=\frac{m}{V p}\left(\frac{g}{m l}\right)$

dimana :

$m$ adalah massa (piknometer + sampel) - massa piknometer kosong

$\mathrm{Vp}$ adalah volume piknometer $100 \mathrm{~mL}$

(Wijaya at al., 2012)

\section{HASIL DAN PEMBAHASAN}

\section{Fermentasi}

Bahan yang digunakan dalam penelitian ini adalah nira atau cairan dari tanaman nira nipah (Nypa fruticans wurmb) yang diambil dari kampung Andai, Kabupaten Manokwari. Nira nipah kemudian dikonversi menjadi etanol melalui proses fermentasi dengan bantuan ragi S. cerevisiae. Pada proses fermentasi dilakukan fariasi waktu yaitu hari kedua, kelima dan ketujuh dengan masing-masing perbandingan 300 gram ragi dalam 4,2 L nira nipah. Hasil dari proses fermentasi selanjutnya dipisahkan antara ragi dan alcohol menggunakan alat evaporator pada suhu $90^{\circ} \mathrm{C}$ selama 8 jam dan selanjutnya diukur kadar alcohol menggunakan alcoholmeter. Dari hasil fermentasi dipilih waktu fermentasi terbaik dengan kadar alcohol tertinggi untuk selanjutnya dilakukan proses destilasi berulang, hasil evaporasi dapat dilihat pada Tabel 4.

Tabel 4 Jumlah Bioetanol Hasil Evaporasi

\begin{tabular}{cccc}
\hline No & $\begin{array}{c}\text { Waktu } \\
\text { fermentasi } \\
\text { (hari) }\end{array}$ & $\begin{array}{c}\text { Jumlah } \\
\text { alkohol } \\
(\mathrm{mL})\end{array}$ & $\begin{array}{c}\text { Kadar } \\
\text { alkohol } \\
(\%)\end{array}$ \\
\hline 1 & 2 & 1539 & 14 \\
2 & 5 & 1290 & 18 \\
3 & 7 & 1335 & 12 \\
\hline
\end{tabular}

Pada Tabel 4 dapat dilihat bahwa waktu fermentasi terbaik yaitu pada hari kelima. Dimana kadar bioethanol yang dihasilkan adalah $18 \%$. Semakin lama waktu fermentasi bioethanol yang dihasilkan semakin murni. namun semakin lama waktu fermentasi glukosa yang diubah menjadi etanol akan diubah juga menjadi asam asetat. Proses perubahan etanol menjadi asam asetatmelalui proses oksidasi terjadi secara bersamaan dengan proses pembentukan etanol (Fardiax, 1992).

\section{Destilasi}

Proses destilasi bertujuan untuk pemisahan larutan berdasarkan titik didih, dimana larutan yang memiliki titik didih kecil akan menguap terlebih dahulu. Menurut (Rutz, 2007) titik didih etanol yaitu $78,4{ }^{\circ} \mathrm{C}$, sedangkan titik didih air $100{ }^{\circ} \mathrm{C}$ jadi etanol akan menguap duluan dari pada air. Sampel hari kelima dengan kadar $18 \%$ sebanyak 1290 $\mathrm{ml}$ selanjutnya didestilasi pada suhu $84-86^{\circ} \mathrm{C}$, dimana titik didih etanol yaitu $78,4^{\circ} \mathrm{C}$ pada suhu diatas $78,4{ }^{\circ} \mathrm{C}$ alcohol akan menguap terlebih dahulu melewati kondensor. Hasil destilasi alcohol dapat dilihat pada tabel 5 .

Tabel 5. Hasil destilasi

\begin{tabular}{cccc}
\hline No & Destilasi & $\begin{array}{c}\text { Jumlah } \\
\text { alkohol }(\mathrm{mL})\end{array}$ & $\begin{array}{c}\text { Kadar } \\
\text { alkohol }(\%)\end{array}$ \\
\hline 1 & 1 & 205 & 72 \\
2 & 2 & 132 & 90 \\
3 & 3 & 117 & 94 \\
\hline
\end{tabular}

Pada tabel diatas dapat dilihat bahwa pada saat destilasi pertama kadar alcohol yang didapat $72 \%$ sebanyak $205 \mathrm{ml}$, pada destilasi kedua kadar alcohol yang didapat 90\% sebanyak $132 \mathrm{ml}$ dan pada destilasi ketiga kadar alcohol yang didapat 94\% sebanyak $117 \mathrm{ml}$. Pada destilasi pertama terjadi peningkatan sebesar 54\%, destilasi kedua peningkatan sebesar $18 \%$ dan destilasi ketiga peningkatan sebesar 3\%. Pada destilasi ulang kadar etanol mengalami peningkatan hal ini disebabkan karena pada saaat destilasi ulang kadar air dalam etanol semakin berkurang (Zenius A at al, 2016).

\section{Rendemen Bioetanol}


Perhitungan rendemen bertujuan untuk mengetahui berapa banyak bioethanol yang dihasilkan dari tanaman nira nipah. Rendemen bioethanol yang terdapat dalam nira nipah yaitu 2,78\% dengan kadar sebesar 94\% . Perhitungan tersebut didapat dari volume produk akhir destilasi nirah nipah $117 \mathrm{~mL}$ dibagi dengan volume awal fermentasi 4,2 L dikali $100 \%$. Untuk mengahasilkan 1 L bioethanol membutuhkan bahan baku nira nipah sebanyak \pm 37 L. Rendemen bioethanol yang dihasilkan dari nira nipah dari segi harga tidak efisien untuk digunakan sebagai bahan bakar, dimana harga bahan baku lebih mahal dibandingkan harga hasil destilasi yang ada.

\section{Densitas Bioetanol}

Densitas bioethanol yang dihasilkan dari proses destilasi yaitu $0,8232 \mathrm{~g} / \mathrm{ml}$. Perhitungan tersebut didapat berat piknometer kosong 44,49 gram berat piknometer tambah sampel 128,81 gram, dimana berat piknometer tambah sampel dikurang berat piknometer kosong didapat berat sampel 82,32 gram dibagi volume piknometer $100 \mathrm{~mL}$. Densitas bioethanol $0,8232 \mathrm{~g} / \mathrm{ml}$ yang diperoleh melebihi densitas absolut yaitu sebesar 0,789 g/ml (Rutz, 2007). Hal ini menunjukan bahwa etanol yang dihasilkan masih belum murni karna masih bercampur dengan air, yang dipengaruhi factor alat serta kurang teliti dalam menjaga kestabilan temperatur destilasi. Nilai densitas berbanding terbalik dengan kadar etanol yang dihasilkan. Semakin rendah nilai densitas menunjukan semakin tinggi kadar etanol (Abtokhi at al, 2015). Nilai densitas $0,8232 \mathrm{~g} / \mathrm{ml}$ diperoleh kadar etanol $93 \%$

\section{Identifikasi Etanol dengan Kromatografi Gas}

Waktu retensi etanol standar pada hasil gas kromatografi (Lampiran 1) dapat dilihat pada tabel 6 .

Tabel 6 Waktu Retensi Etanol Standar

No Kadar etanol standar Waktu retensi $(\%)$

\begin{tabular}{lll}
\hline 1 & 30 & 3,757 \\
2 & 40 & 3,763 \\
3 & 50 & 3,764 \\
4 & 60 & 3,767 \\
5 & 70 & 3,773 \\
\hline
\end{tabular}

Pada tabel 5 diatas dapat dilihat bahwa rata-rata waktu retensi etanol standar adalah 3,764 sedangkan untuk waktu retensi sampel dapat dilihat pada gambar 6 berikut.

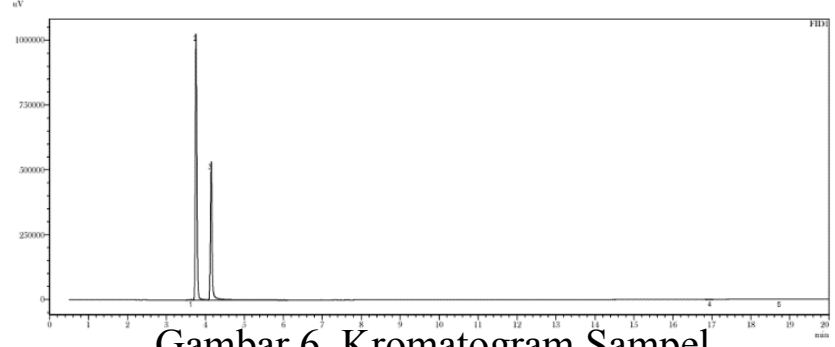

Gambar 6. Kromatogram Sampel

Dari data kromatogram diatas didapatkan waktu retensi untuk sampel yaitu 3,761. Sampel memiliki waktu retensi yang hampir sama dengan waktu retensi dari etanol standar yaitu, sampel 3,761 dan etanol standar 3,764. Dari data waktu retensi dapat disimpulkan bahwa sampel tersebut adalah etanol. Peak yang muncul pada kromatogram ada dua yakni peak etanol dan peak propanol. Menurut (Fitriana, 2009) kromatogram yang menghasilkan 2 peak menunjukan bahwa etanol yang diperoleh memiliki kemurnian yang tinggi.

\section{Analisis Kadar Bioetanol dengan Kromatografi Gas}

Untuk perhitungan kadar dengan motode kromatografi gas menggunakan persamaan garis yang didapat dari kurva standar. Kurva standar dibuat dengan meginjeksikan etanol standar 30\%, 40\%, 50\%, 60\%, 70\% yang telah ditambahkan propanol. Hasil kromatogram selanjutnya dihitung perbandingan antara luas area etanol dan luas area propanol. Berikut tabel rasio kadar etanol standar dengan perbandingan luas area. 
maka dapat dihitung kadar etanol dengan mengsubtitusikan luas sampel banding luas area propanol. Hasil perhitungan kadar etanol dalam sampel dapat dilihat pada tabel berikut.

Tabel 7 Rasio Area Standar Etanol dan Propanol

\begin{tabular}{ccccc}
\hline No & $\begin{array}{c}\text { Kadar } \\
\text { etanol } \\
\text { standar } \\
(\%)\end{array}$ & $\begin{array}{c}\text { Area } \\
\text { etanol }\end{array}$ & $\begin{array}{c}\text { Area } \\
\text { propanol }\end{array}$ & $\begin{array}{c}\text { Perbandingan } \\
\text { etanol dan } \\
\text { propanol }\end{array}$ \\
\hline 1 & 30 & 4047046 & 2921563 & 1,3852 \\
2 & 40 & 6810762 & 3010805 & 2,2621 \\
3 & 50 & 8345653 & 3263957 & 2,5569 \\
4 & 60 & 10677800 & 3311650 & 3,2243 \\
5 & 70 & 14083972 & 4365159 & 3,3699 \\
\hline
\end{tabular}

Pada tabel 7 diatas hanya menggunakan tiga standar etanol yang digunakan untuk membuat kurva standar yakni 30\%, 50\%, 70\%. Hal ini dikarenakan pada saat membuat kurva standar nilai $\mathrm{R}$ yang dihasilkan kurang baik sehinnga dihapus dua data yakni $40 \%$ dan $60 \%$. Nilai R berpengaruh terhadap konsentrasi yang didapat, nilai $\mathrm{R}$ yang baik yaitu mendekati 1 . Dari data tabel 7 diatas dibuat kurva standar dengan menghubungkan konsentrasi etanol standar sebagai sumbu $\mathrm{X}$ vs luas area etanol standar (Ast) banding luas area propanol sebagai internal standar (Aist) sebagai sumbu Y. berikut adalah gambar kurva standar.

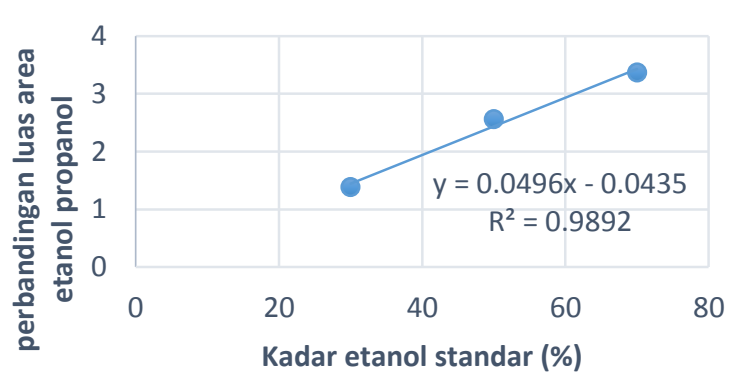

Gambar 7. Kurva Standar Etanol vs Perbadingan Luas Area

Dari kurva diatas didapat persamaan garis $\mathrm{Y}=0,0496 \mathrm{X}-0,0435$ dengan nilai korelasi $\mathrm{R}=0,9892$. Dari persamaan garis yang didapat
Tabel 8 Hasil Perhitungan Kadar Sampel

\begin{tabular}{cccccc}
\hline $\mathrm{N}$ & $\begin{array}{c}\text { Area } \\
\text { etanol } \\
\text { (Ast) }\end{array}$ & $\begin{array}{c}\text { Area } \\
\text { Propan } \\
\text { ol } \\
\text { (Aist) }\end{array}$ & $\begin{array}{c}\text { etanol/propa } \\
\text { nol }\end{array}$ & $\begin{array}{c}\text { konsentr } \\
\text { asi }\end{array}$ & $\begin{array}{c}\text { Pengence } \\
\text { ran 2x }\end{array}$ \\
\hline 1 & 70915 & 29893 & 2,3722 & 46,9516 & 93,9 \\
& 80 & 27 & & & \\
\hline
\end{tabular}

Hasil perhitungan dengan persamaan garis didapat kadar alcohol yaitu 46,9515\% kemudian dikali dua sebagai factor pengenceran sampel, dimana pada saat menginjeksikan sampel ke alat kromatografi gas sebelumnya sampel diencerkan dua kali, maka kadar etanol dalam sampel yaitu 93,9\%. Hasil perhitungan kadar etanol dengan kromatografi gas hampir sama dengan hasil pengukuran alcohol menggunakan alat alcoholmeter dimana perhitungan menggunakan kromatografi gas adalah $93,9 \%$ sedangkan pengukuran menggunakan alcoholmeter adalah 94\%. Hal ini menunjukan bahwa pada saat pengukuran menggunakan alcoholmeter sampel yang diukur adalah etanol. Dari hasil penelitian terdahulu kadar etanol dalam nira nipah yang dihasilkan dari proses destilasi yaitu sebesar $96 \%$ (Villarul et al, 2017). Dalam (Fitriana, 2009) kadar etanol yang dihasilkan dari proses destilasi hari kelima adalah 94,98\%.

\section{KESIMPULAN}

Hasil penelitian ini dapat disimpulkan bahwa sampel mengadung etanol dilihat dari waktu retensi, dimana waktu retensi sampel 3,761 hampir sama dengan waktu retensi etanol standar 3,764. Kadar etanol yang dihasilkan adalah 93,9\% sebanyak $117 \mathrm{~mL}$ dari 4,2 L nira nipah dan memiliki densitas sebesar 0,8232 $\mathrm{g} / \mathrm{ml}$. Untuk menghasilkan $1 \mathrm{~L}$ etanol dengan 
kadar 93,9 \% membutuhkan bahan baku nira nipah $\pm 37 \mathrm{~L}$.

\section{DAFTAR PUSTAKA}

A Abtokhi., Khodijah S. 2015. Analisis Pengaruh Variasi Presentase Ragi (Saccharomyces Cerevisiae) Dan Waktu Pada Proses Fermentasi Dalam Pemanfaatan Duckweed (Lemna Minor) Sebagai Bioethanol. Jurnal Neutrino. 7(2) : 27-31

Dahlan., Muhammad H., Dewi D., Ismadyar. 2009. Pemekatan Nira Nipah Menggunakan Membran Selulosa Asetat. Jurnal Teknik Kimia Universitas Sriwijaya : Palembang.

Delly J., Hasbi M., Zenius A. 2016. Analisa Bioetanol Dari Nira Aren Menggunakan Destilasi Fraksinasi Ganda Sebagai Bahan Bakar. Jurnal Ilmiah Mahasiswa Teknik Mesin, Vol 2, No 2 : 1-7.

Fitriani L. 2009. Karakteristik Faktor-faktor yang Mempengaruhi Masalah Makan pada Anak PAUD Permata Bunda Jakarta Timur. Jakarta : Politeknik Kesehatan Jakarta.

Fardiax S. 1992. Mikrobiologi Pangan Gramedia Pustaka Utama. Jakarta

Feryanto D. 2009. Pengukuran Alkoholmeter. http//www.alkoholmeter.meterlak.com diakses pada 18 Juli 2020.

Khaidir. 2011. Modifikasi Zeolit Alam Sebagai Material Molecular Sieve dan Aplikasinya pada Proses Dehidrasi
Bioetanol. Disertasi Doktor. Institut Pertanian Bogor: Bogor.

Mortimer M., Taylor P. 2002. Chemical Kinetics and Mechanism. Cambridge : RSC.

Niastiwa, Fransisca., dkk. 2013. Pemanfaatan Nira Aren Menjadi Bioetanol Sebagai Bahan Bakar Alternatif. Banten: Cilegon. Universitas Sultan Ageng Tirtayasa

Oniki S. 2006. Bioetanol : Indrustrial Production Process and Recent Studies, [online].Tersedia:www.public.iastate.edu/ -tge/courses/ces521/sonuki.pdf.

Rutz D., Jansen R. 2007. Biofuel Technology Handbook. Jerman : WIP Renewable Energies, Sylvensteinstr.

Tresnawati H. 2009. Motivasi Wanita Perajin Gula Nipah Dalam Meningkatkan Pendapatan Rumah Tangga di Desa Nusadadi, Kecamatan Simpiuh, Kabupaten Banyumas. Skripsi. Fakultas Pertanian. Universitas Soediman.

Villarul T N., Chairul., Yenti S R.2017. Pemurnian Bioetanol Hasil Fermentasi Nira Nipah Menggunakan Proses Destilasi-Adsorpsi Menggunakan Adsorben CaO. Jom FTEKNIK. Vol 4, No $2: 1-6$

Walidah T.,Chairul., Amri A. 2015. Pemurnian Bioetanol Hasil Fermentasi Nira Nipah dengan Proses DistilasiAdsorpsi Menggunakan Bentonit Teraktivasi. JOM FTEKNIK Vol 2, No 1 : 1-6.

Wijaya I A S., Arthawan G K A., Novitasari A. 2012. Potensi Nira Kelapa Sebagai Bahan Baku Bioetanol. Jurnal Bumi Lestari. 8592 